\title{
INDIGENOUS TUBE EXCHANGER: BE SAFE BE SURE
}

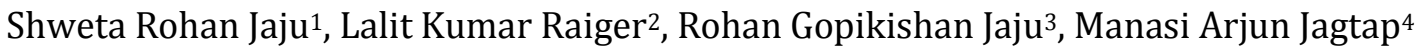

\section{HOW TO CITE THIS ARTICLE:}

Shweta Rohan Jaju, Lalit Kumar Raiger, Rohan Gopikishan Jaju, Manasi Arjun Jagtap. "Indigenous Tube Exchanger: Be Safe Be Sure". Journal of Evolution of Medical and Dental Sciences 2014; Vol. 3, Issue 50, October 06; Page: 11849-11852, DOI: 10.14260/jemds/2014/3559

INTRODUCTION: Airway exchange catheter is utilized to facilitate extubation or exchange of endotracheal tube ${ }^{1}$.Various studies show that it is better to extubate the patient with airway tube exchange catheter when patient has history of difficult intubation or anticipated re-intubation. ${ }^{2}$

KEYWORDS: Difficulty in extubation; cost effective, Airway exchange catheter, not readily available, PVC ureteric catheter.

AIMS AND OBJECTIVE: We report a case which had difficulty in intubation and was extubated on an indigenous airway tube exchanger.

MATERIAL AND METHODS: Permission of the ethical committee was taken. A 40 years obese female patient, weighing $85 \mathrm{~kg}$ was posted for left ear tympanoplasty, had mouth opening of 2 fingers, no loose teeth, short neck, subluxation of jaw-zero station, mallampati grade 3, free neck movement, Cormack lehane grade 3 and was intubated with no. 7 cuffed endotracheal tube without any trauma with the help of guide wire and external laryngeal pressure.

On completion of surgery, anesthesia was reversed. Patient was conscious, tolerating tube and saturation was $92 \%$ on air i.e., without oxygen. In anticipation of post-extubation airway management problem patient was extubated on indigenous airway tube exchange catheter.

INDIGENOUS TUBE EXCHANGER CATHETER: We took the PVC sheath of a ureteric catheter/ guide wire which was cut in $80 \mathrm{~cm}$ length (approximately 2.5 times of the length of endotracheal tube). We had marked it at every one $\mathrm{cm}$ distance up to $30 \mathrm{~cm}$; to guide the depth of insertion (fig. A). It is a rigid tube with a lumen of $3 \mathrm{~mm}$ internal diameter and not easy compressible.

This tube exchanger was passed through the endotracheal tube up to $26 \mathrm{~cm}$ mark/depth (length of the endotracheal tube, fig. B). Patient was extubated keeping the tube exchanger in position (fig. C, D) and a connecter of no 3 endotracheal tubes was attached on its distal end. Breathing circuit was attached to this connecter. Patient was observed for half an hour. She tolerated the presence of the catheter without episodes of coughing and without complaint of discomfort. After the patient was fully alert, she was extubated uneventfully.

DISCUSSION: Airway exchange catheter (AEC) is commercially available (company: cooks, VBM India etc). AEC is designed to facilitate ease of extubation; endotracheal tube can be exchanged over it (mostly in ICU settings requiring prolonged ventilation). It also provides a patent lumen which may serve to insufflate oxygen, jet ventilation, and direct EtCo2 measurement. ${ }^{3,4}$

However tube exchangers are not readily available in most of the set-ups in developing countries. Moreover PVC ureteric catheter sheath is easily available. 


\section{CASE REPORT}

RESULTS: Patient was extubated uneventfully with the help of the indigenous tube exchanger. It may constitute a reliable and cost effective alternative to commercially available tube exchanger in emergency conditions without any harmful effects on the patient.

\section{REFERENCES:}

1. Hagberg CA, Regan T. Extubation of the difficult airway. In: Hagberg CA, Handbook of Difficult Airway Management ed, 2000.Churchill Livingstone: Philadelphia. Pg: 373-87.

2. Caplan RA, Benumof JL, Berry FA, et al. Practice guidelines for management of the difficult airway: a report by the American Society of Anesthesiologists Task Force on Management of the Difficult Airway. Anaesthesiology. 1993; 78: 597-602.

3. Moyers G. Use of the Cook airway exchange catheter in "Bridging" the potentially difficult extubation: A case report. AANA journal. 2002; 70 (4): 275-8.

4. Ward's Anaesthetic equipment, 5 ${ }^{\text {th }}$ edition. Elsevier Saunders, year 2005. Pg. 209.

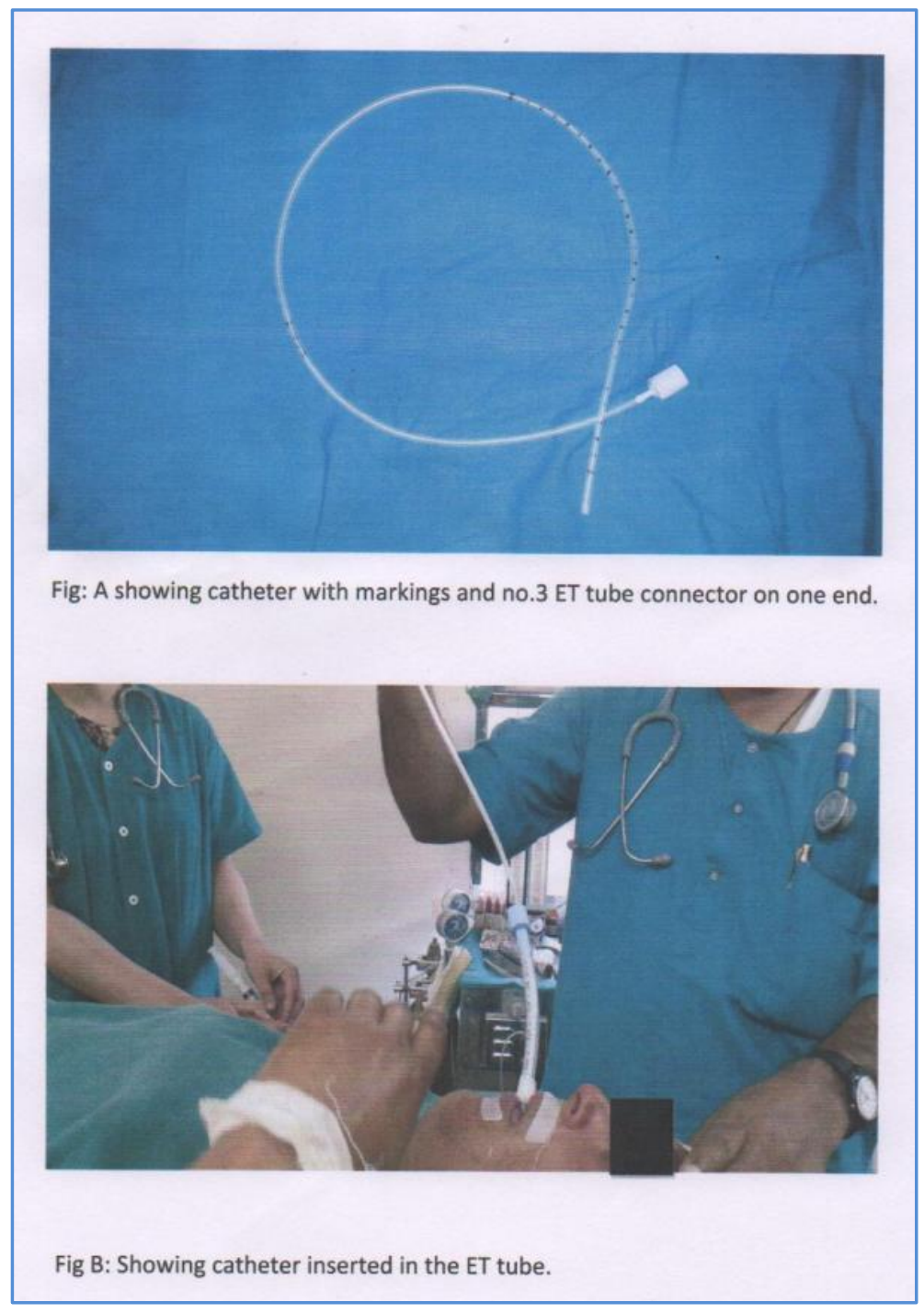




\section{CASE REPORT}

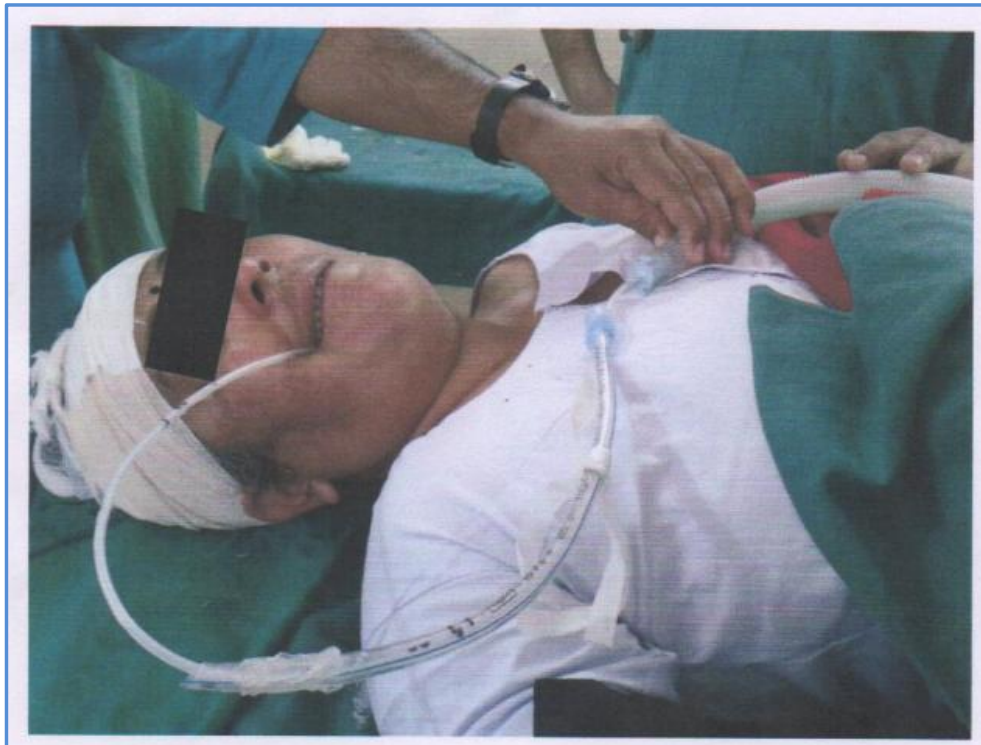

Fig C: Showing extubation performed over the catheter while the catheter is connected to the bains circuit.

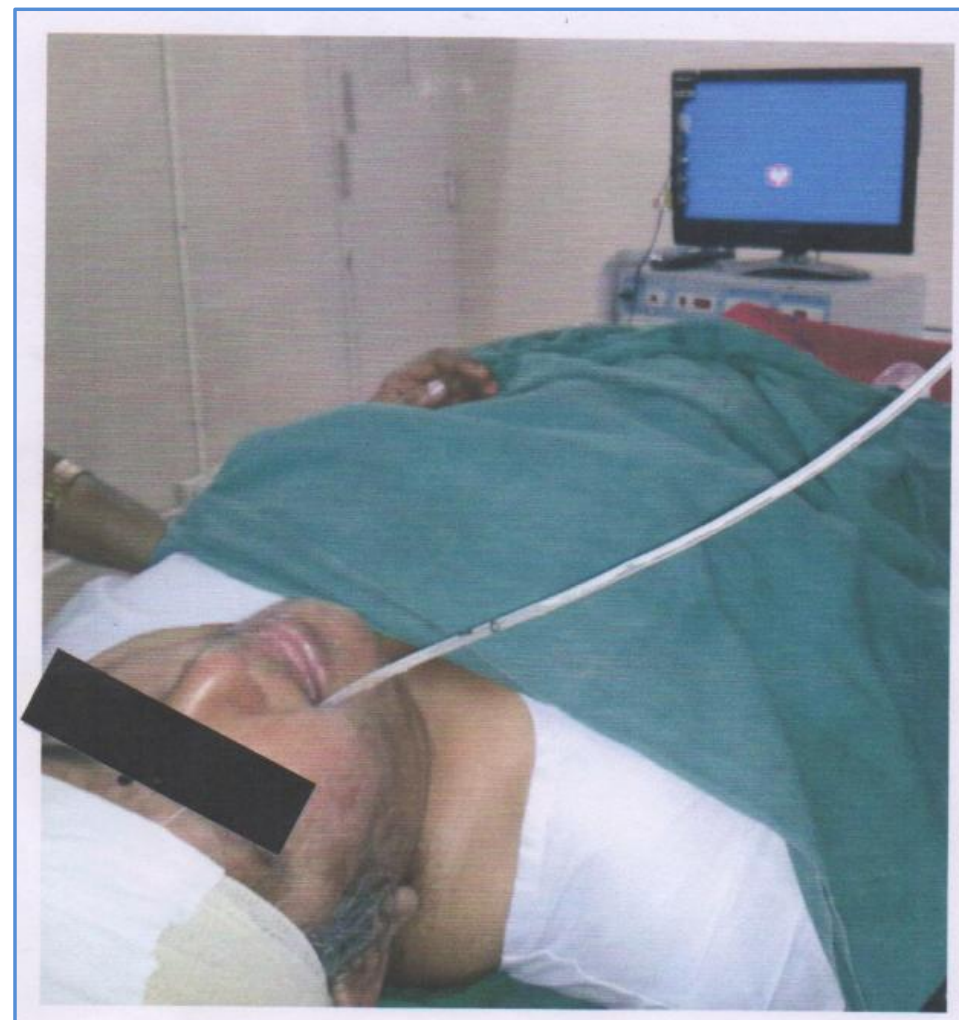

Fig D: After extubation, patient with indigenous tube exchange catheter. 


\section{AUTHORS:}

1. Shweta Rohan Jaju

2. Lalit Kumar Raiger

3. Rohan Gopikishan Jaju

4. Manasi Arjun Jagtap

\section{PARTICULARS OF CONTRIBUTORS:}

1. Senior Resident, Department of Anaesthesia, Rabindra Nath Tagor Medical College.

2. Professor \& Unit Head, Department of Anaesthesia, Rabindra Nath Tagor Medical College.

3. Junior Resident, Department of Urology, Bombay Hospital Institute of Medical Sciences.
4. $1^{\text {st }}$ Year Student, Department of Prosthodontics, Yerla Medical Trust.

\section{NAME ADDRESS EMAIL ID OF THE CORRESPONDING AUTHOR:}

Dr. Shweta Rohan Jaju,

B-2, Sun-Shine Apt,

Khadak Pada Circle,

Kalyan (W),

Maharashtra-421301.

Email: drshweta.jagtap@yahoo.com

Date of Submission: 19/09/2014.

Date of Peer Review: 20/09/2014.

Date of Acceptance: 29/09/2014.

Date of Publishing: 06/10/2014. 